\title{
Nucleotide excision repair gene polymorphisms and prognosis of non-small cell lung cancer patients receiving platinum-based chemotherapy: A meta-analysis based on 44 studies
}

\author{
DONGNING HUANG ${ }^{1}$ and YANG $\mathrm{ZHOU}^{2}$ \\ ${ }^{1}$ Department of Oncology, Fourth Affiliated Hospital of Guangxi Medical University, Liuzhou, Guangxi 545005; \\ ${ }^{2}$ School of Public Health, Guangxi Medical University, Nanning, Guangxi 530021, P.R. China
}

Received March 2, 2014; Accepted May 5, 2014

DOI: $10.3892 /$ br.2014.282

\begin{abstract}
Genetic variations are linked to DNA repair ability and varied drug metabolism that largely affects the prognosis of antineoplastic agents, including platinum. The purpose of the present meta-analysis was to determine the roles of the genetic variants of the nucleotide excision repair genes on the prognosis of platinum-based chemotherapy in patients with non-small cell lung cancer (NSCLC). A meta-analysis was performed, including 44 original studies with a total number of 5,944 patients with NSCLC according to the search strategy. The tumor responses [complete response, partial response, stable disease (SD) and progressive disease (PD)] were estimated and the Stata package was used for the comprehensive quantitative analyses. The results showed that the XPG C46T polymorphism was significantly associated with tumor chemotherapy when SD or PD was considered as a non-response [TT vs. CC: risk ratio (RR), 1.31; 95\% confidence interval $(\mathrm{CI}), 1.14-1.5$; and $\mathrm{P}=0.00$; TT/CT vs. $\mathrm{CC}$ : RR, 1.23; 95\% CI, 1.11-1.36; and $\mathrm{P}=0.00$; and TT vs. CC/CT: RR, 1.22; 95\% CI, 1.11-1.36; and $\mathrm{P}=0.00]$. No significant association between the ERCC1 C118T/C8092A XPDLys751Gln and $X P A A 23 G$ polymorphisms and tumor response was found. There was also no evidence found to support the use of the ERCC1 C118T/C8092A XPDLys751Gln and XPA A23G polymorphisms as prognostic predictors of platinum-based chemotherapies in NSCLC in the meta-analysis. For the $X P G$ C46T polymorphisms, a significant association with an objective response was detected. Multiple and large-scale studies are required to further investigate the association between biomarkers and tumor prognosis.
\end{abstract}

Correspondence to: Yang Zhou, School of Public Health, Guangxi Medical University, 6 Binhu Road, Nanning, Guangxi 530021, P.R. China

E-mail: gxzhouy123@163.com

Key words: platinum-based chemotherapy, non-small cell lung cancer, nucleotide excision repair, polymorphism, meta-analysis

\section{Introduction}

Lung cancer is currently the most common malignancy and is a leading cause of mortality worldwide (1-2). The mechanism of this type of carcinogenesis remains to be fully elucidated. Tobacco smoking has been suspected to be the most significant cause of lung cancer. However, only 1 in 10 smokers develop lung cancer, demonstrating that it is likely that genetic susceptibility also plays a significant role (3). Therefore, the detection of genetic polymorphisms should be taken into consideration to explain individual differences in lung cancer susceptibility. Non-small cell lung cancer (NSCLC) represents $\sim 80 \%$ of primary lung cancer cases and approximately two-thirds of these patients are diagnosed at an advanced stage (4). Several effective chemotherapeutic agents are available for treatment and platinum-based chemotherapy, including cisplatin and carboplatin, is the standard initial treatment regimen for NSCLC (5). Evidence from NSCLC trials involving unselected patients has shown that the efficacy of the regimen used is reported to be only $30-40 \%$ (6). Although the disease stage at diagnosis is the major prognostic predictor, there are variations in survival rates among patients who begin treatment at a similar disease status and undergo similar treatment regimens. Findings of a previous study have indicated that genetic factors may also affect the effectiveness of treatment (7).

Pharmacogenetics plays a significant role in current cancer chemotherapy and it has been reported that the prognosis can be partly influenced by genes (8). These antineoplastic agents contribute to the inhibition of DNA replication and transcription due to the formation of adducts and covalent cross-links between DNA-double strands that lead to DNA damage. These adduct and cross-links can be repaired by complex molecules in the nucleotide excision repair (NER) pathway, including ERCC1, XPD, XPF and XPG gene-encoded proteins. Therefore, NER gene polymorphisms may be able to predict the outcome and prognosis in individual patients with NSCLC undergoing platinum chemotherapy.

Mutations are early events in carcinogenesis and for various types of cancer the defect of DNA repair is a risk factor (9). The maintenance of genome integrity is extremely significant for the survival of all organisms, but DNA is regularly damaged by various types of endogenous and exogenous mutagens. 
The DNA repair gene system is crucial in protecting against gene mutation caused by carcinogenesis. The deficiency in the capacity of DNA repair may result in birth defects, cancer and a reduced lifespan (10). DNA repair consists of at least four types, including damaged base excision repair, DNA-NER, mismatch repair and double-strand break repair (11). Among these, NER is a highly adaptable and advanced DNA damage removal pathway that impedes the deleterious effects of a multitude of DNA lesions, including major types of environmental-induced damage. In eukaryotic cells, the process requires $>30$ proteins to perform at various steps (12).

In recent years, an increasing body of epidemiological studies $(1,3,5)$ have demonstrated that the potential role of polymorphisms of the genes in the NER pathway may be associated with the clinical prognosis of patients with NSCLC receiving platinum-based chemotherapies in China. However, the results were shown to be inconclusive. In order to investigate the effect of these genetic factors, including ERCC1, XPD/ERCC2, XPA and $X P G$, on the prognosis of platinum-based chemotherapy, a meta-analysis was performed, to the best of our knowledge, for the first time with regards to the key genes of DNA repair and metabolism in the Chinese population.

\section{Materials and methods}

Literature search strategy and selection criteria. A comprehensive literature search was performed using the PubMed, Embase, Chinese National Knowledge Infrastructure (CNKI) (http://www.cnki.net/) and Wanfang databases (http://www. wanfangdata.com.cn/) to identify the studies investigating the associations between the NER gene variants and NSCLC risk in the Chinese population that were published prior to October 1 , 2013. The following terms were used in the search: Lung cancer, non-small cell lung cancer or NSCLC; in combination with polymorphisms, variants or mutation; ERCC1, XPD/ERCC2, $X P A$ or $X P G$; platinum or cisplatin and carboplatin; and in combination with China or Chinese. The searches were limited to human studies and the Chinese population. The gender and average ages of patients in each original study were not taken into consideration. All the references of the review and original articles on this topic were also checked. When multiple publications reported the same or overlapping data, only the most updated study with the largest sample size was selected.

The studies included in the meta-analysis had to meet all the following inclusion criteria: i) Cancer should be confirmed as NSCLC; ii) treatment regimens were platinum-based chemotherapies; and iii) the original data were presented with the calculation of risk ratios (RRs) with corresponding $95 \%$ confidence intervals (CIs) or other available data for estimating RR $(95 \%$ CI).

Exclusion criteria were: Studies without genotype or allele data, case reports, studies pertaining to small cell lung cancer, studies containing overlapping data, non-human studies, interim analyses, comparisons of laboratory methods, editorials and review articles (including meta-analyses). Any missing information was obtained by contacting the corresponding authors in all cases and the studies were not considered if critical missing information could not be obtained following repeated requests. The method for how the polymorphism was detected was not limited and the evaluation criteria for the tumor response were accepted for all subjects [the World Health Organization (WHO) criteria or the Response Evaluation Criteria in Solid Tumors (RECIST)]. In terms of the definition of the tumor response, two different standards were allowed and they were based on the aforementioned evaluation. If certain studies did not obtain the crucial information of drug response and/or state of survival rate, the corresponding authors were contacted to request the relevant data.

Data extraction. Data were extracted and entered into a database. Two investigators (DH and YZ) searched the initially relevant literature with keywords in the titles or abstracts and eligible studies were determined. When extracting data from each eligible study independently to ensure the accuracy of data, any discordance with regard to results was resolved when agreement was reached by the two investigators. All the studies were evaluated by titles and abstracts initially, prior to further evaluation for particular studies.

Data were collected with regards to the genotypes of ERCC1 C118T/C8092A, ERCC2/XPD A751C, XPA G23A and $X P G C 46 T$, and the following information was extracted from each of the eligible studies: First author, year of publication, sample size of genotyped cases, gender (male/female), median (or mean) age and (range) year, smoking/no-smoking, genotyping methods, chemotherapy regimens, evaluation criteria, histology, clinical stage and genotype studied.

Statistical analysis. The RR for the tumor response [complete response $(C R)+$ partial response $(\mathrm{PR})$ vs. stable disease (SD) + progressive disease (PD) or $\mathrm{CR}+\mathrm{PR}+\mathrm{SD}$ vs. $\mathrm{PD}]$ by adopting the WHO or the RECIST criteria (13) was estimated subsequent to accepting the aforementioned chemotherapy treatment.

Two models of meta-analysis, the random-effects [DerSimonian and Laird (14)] and the fixed-effects models (Mantel-Haenszel), were performed to calculate the pooled RRs in the present study. For each comparison, statistical heterogeneity among the studies was evaluated by calculating the $\chi^{2}$-based Q statistical test (Cochran's Q statistics), when $\mathrm{P}<0.1$ heterogeneity existed (15). $\mathrm{I}^{2}$ statistics were calculated to assess the degree of between-study inconsistency due to heterogeneity rather than by chance when $\mathrm{I}^{2}>50 \%$ indicated the statistical significance (16). When heterogeneity existed, the random-effects model was chosen to evaluate the overall or pooled estimate of risk (RRs). The fixed-effects model was chosen when heterogeneity detected between studies had no significance.

An evaluation of potential publication bias was performed by visual inspection with the funnel plots and statistical evaluation with Begg and Egger's unweighted regression tests (17-18). Possible publication bias was indicated by an asymmetric plot. Stata version 9.0 (StataCorp, College Station, TX, USA) was implemented for statistical analyses. All the P-values were two-tailed and $\mathrm{P}<0.05$ was considered to indicate a statistically significant difference.

\section{Results}

Identification and characteristics of included studies. There were 102 relevant publications identified through the literature 


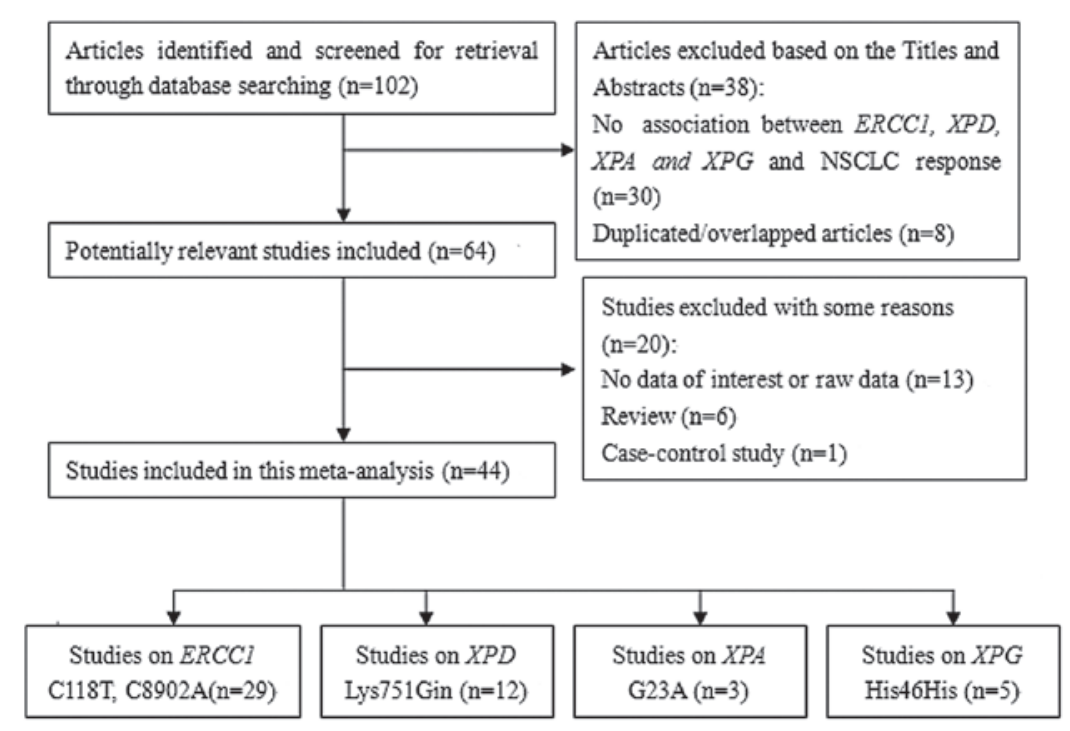

Figure 1. Process of inclusion and exclusion of studies for ERCC1,XPD, XPA and XPG and the concise reasons for all selections.

search and selection was based on the inclusion criteria following the initial screening. Among these, 64 potentially relevant studies were identified subsequent to carefully reading titles and abstracts. A total of 20 studies were excluded for the following reasons: One was a case-control study, six were reviews, 13 had no data of interest or raw data and eight studies were excluded due to duplicated/overlapping studies. No additional studies were identified from the references cited in the published studies that were searched for manually. Twenty-nine studies concerning the ERCC1 C118T/C8092A polymorphism (19-47), eight with the $C 8092 A$ polymorphism $(19,22,24,31,39,40,48-49), 12$ with the $X P D A 751 C$ polymorphism $(26,27,39,47,49-56)$, three with $X P A$ G23A (57-59) and five studies with XPG His46His (58-62). The specific process of the inclusion and exclusion of eligible studies is shown in Fig. 1. The main characteristics of the studies identified are shown in Table I.

\section{Overall analysis of data}

Tumor response of ERCC1 C118T/C8092A polymorphisms (non-response: $S D$ or PD). A total of 24 studies were eventually included with a total sample size of 2,585 patients. Data showed that there was no significant association between ERCC1 C118T polymorphisms and tumor response in the present study analyses under the four comparison models [TT vs. CC: RR (95\% CI), 1.01 (0.7-1.45), P=0.976; CT vs. CC: RR (95\% CI), 0.91 (0.78-1.05), P=0.199; CT/TT vs. CC: RR (95\% CI), 0.95 (0.85-1.06), $\mathrm{P}=0.386$; and TT vs. CC/CT: RR (95\% CI), 1.06 (0.91-1.23), $\mathrm{P}=0.463$; Table II and Fig. 2]. There was significant heterogeneity observed between studies in the initial fixed model in three genetic contrasts for which a random model was required (TT vs. CC: $\mathrm{I}^{2}=61 \%$; CT vs. $\mathrm{CC}: \mathrm{I}^{2}=51.1 \%$; and CT/TT vs. CC: $\mathrm{I}^{2}=66.9 \%$; Table II), except for the recessive model (TT vs. CC/CT: $\mathrm{I}^{2}=39.8 \%$; Table II). In addition, publication bias was detected in Egger's test (TT vs. $\mathrm{CC}$ : $\mathrm{P}=0.028$; and TT vs. CC/CT: $\mathrm{P}=0.029$ ), but not in the other models (CT vs. CC: $\mathrm{P}=0.251$; and $\mathrm{CT} / \mathrm{TT}$ vs. $\mathrm{CC}: \mathrm{P}=0.973$ ) (data not shown).

Eight studies were included with a total sample size of 1,102 patients. Data showed that the ERCC1 C8092A polymorphism was not associated with tumor response in this analysis [AA vs. CC: RR (95\% CI), 1.09 (0.88-1.35), $\mathrm{P}=0.412$; CA vs. CC: RR (95\% CI), 0.94 (0.81-1.1), P=0.431; AA/CA vs. CC: RR (95\% CI), 1.11 (0.91-1.35), $\mathrm{P}=0.328$; and AA vs. CC/CA: RR (95\% CI), 0.96 (0.88-1.05), P=0.377; Table II]. No significant between-study heterogeneity was observed in the initial fixed model and therefore a random model was not performed, resulting in $\mathrm{P}$-values of 0 . In addition, no publication bias was detected in Egger's test (AA vs. CC: $\mathrm{P}=0.53$; CA vs. $\mathrm{CC}$ : $\mathrm{P}=0.106$; and $\mathrm{AA}$ vs. $\mathrm{CC} / \mathrm{CA}: \mathrm{P}=0.397)$, but not in the dominant model (AA/CA vs. $\mathrm{CC}: \mathrm{P}=0.044$ ) (data not shown).

Tumor response of ERCC1 C118T polymorphisms (non-response: $P D)$. Seven studies were included with a total sample size of 729 patients. Data showed that ERCC1 C118T polymorphisms were not associated with the tumor response in this analysis under the four comparison models (TT vs. CC: RR (95\% CI), 0.65 (0.3-1.41), $\mathrm{P}=0.276$; CT vs. CC: RR (95\% CI), 1 (0.5-2), P=0.995; CT/TT vs. CC: RR (95\% CI), 0.83 (0.64-1.07), $\mathrm{P}=0.149$; and TT vs. CC/CT: RR (95\% CI), 0.67 (0.31-1.44), $\mathrm{P}=0.304$; Table III). Significant between-study heterogeneity was observed in the initial fixed model and then a random model was performed $\left(\mathrm{I}^{2}=75 \%\right)$ under the heterozygote comparison model. In addition, no publication bias was detected with a $\mathrm{P}>0.05$ in Egger's test, and no significant outcome of influence analysis was observed (data not shown).

Tumor response of XPD A751C polymorphisms (non-response: $S D$ or $P D)$. Twelve studies were included with a total sample size of 2,043 patients. Overall, the meta-analysis showed that there was no statistically significant association between the XPD A751C polymorphism and tumor response for all the genetic models (GlnGln vs. LysLys: RR=1.21,95\% CI: 0.92-1.59, $\mathrm{P}=0.183, \mathrm{I}^{2}=0.0 \%$ for heterogeneity test; LysGln vs. LysLys: $\mathrm{RR}=1.08,95 \% \mathrm{CI}: 0.96-1.22 \mathrm{P}=0.182, \mathrm{I}^{2}=33.1 \%$ for heterogeneity test; the recessive model, GlnGln vs. LysLys/LysGln: $\mathrm{RR}=1.16,95 \% \mathrm{CI}: 0.89-1.52, \mathrm{P}=0.272, \mathrm{I}^{2}=0 \%$ for heterogeneity test; and the dominant model, GlnGln/LysGln vs. LysLy: $\mathrm{RR}=1.02$, 95\% CI: $0.92-1.13, \mathrm{P}=0.714, \mathrm{I}^{2}=43.7 \%$ for heterogeneity test; Table II and Fig. 3). In addition, no publication bias 


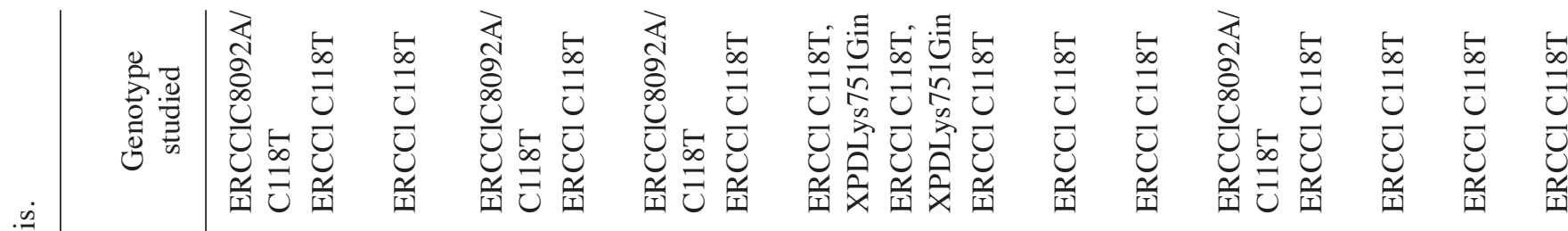

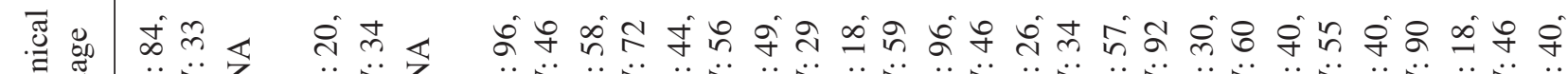

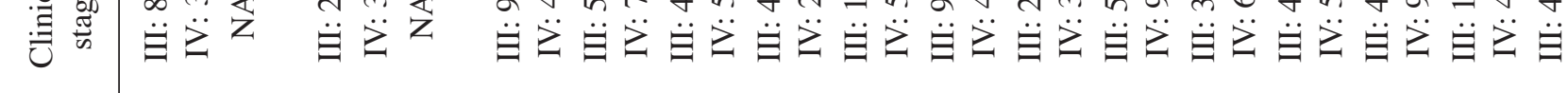

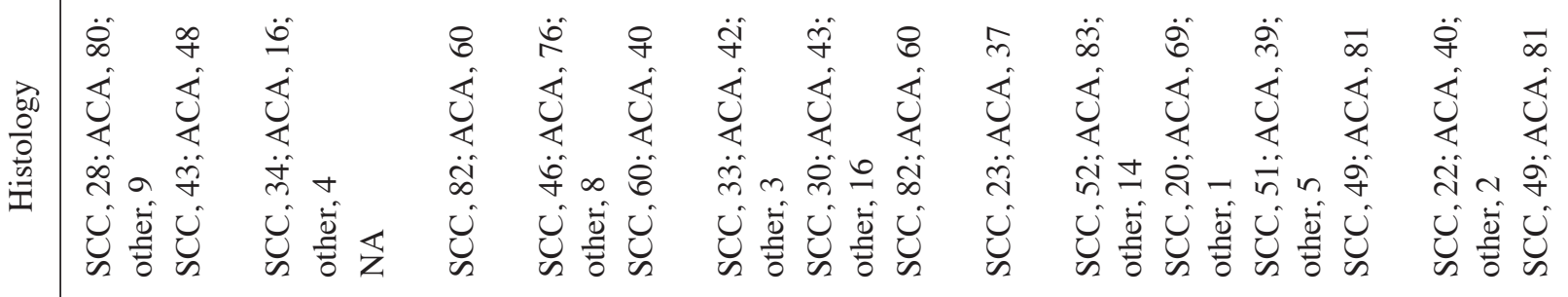

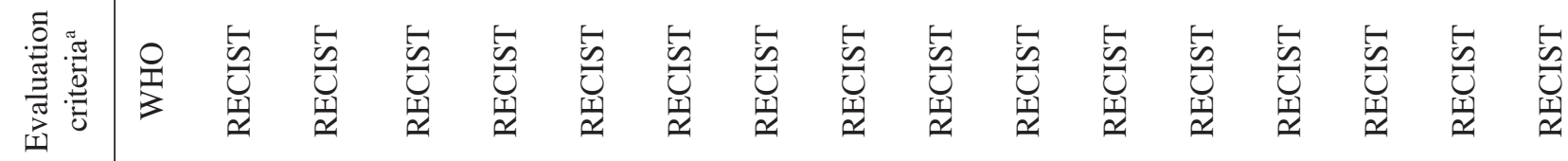

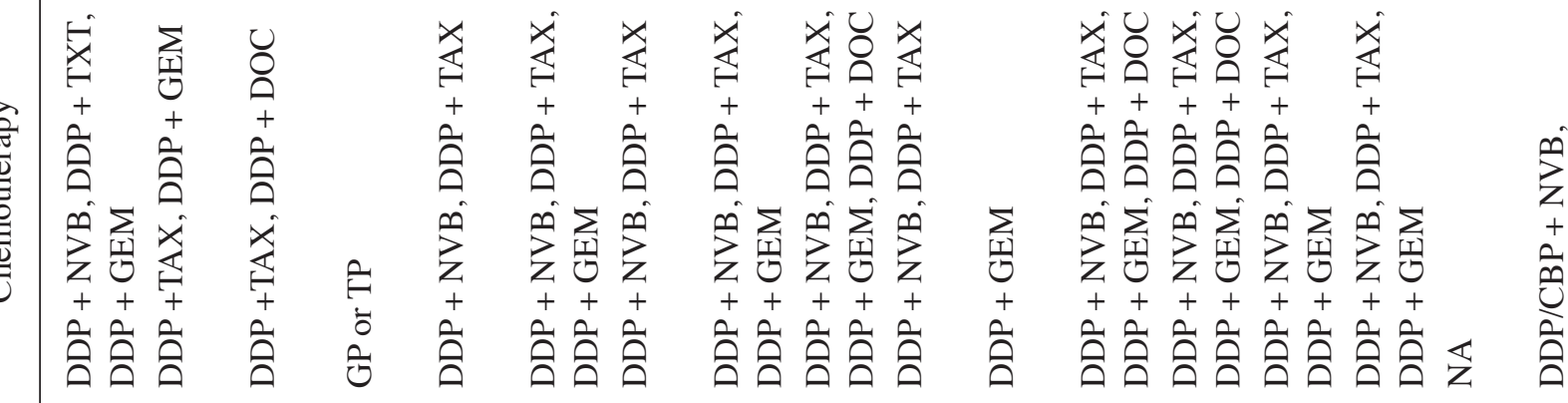

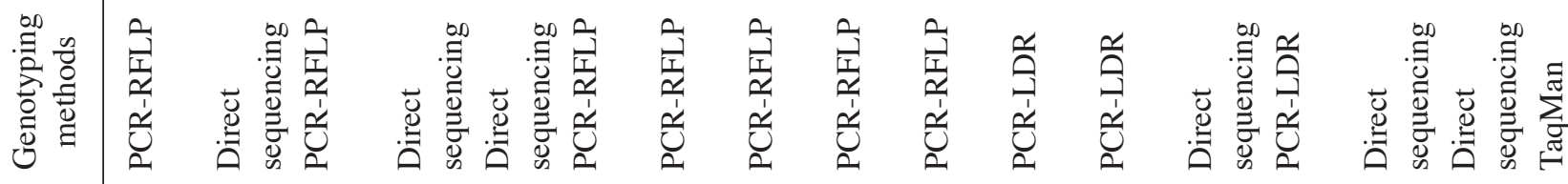

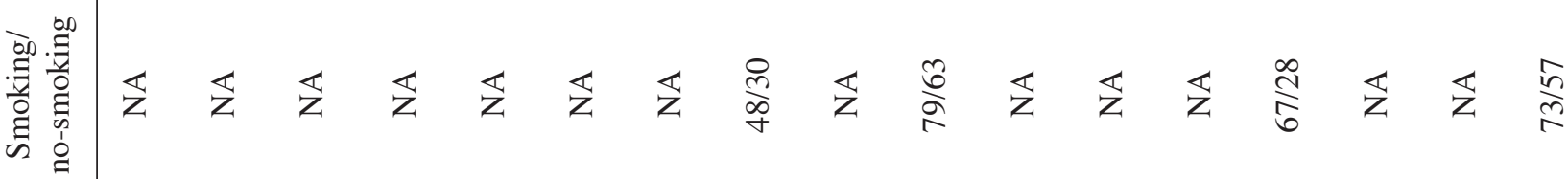

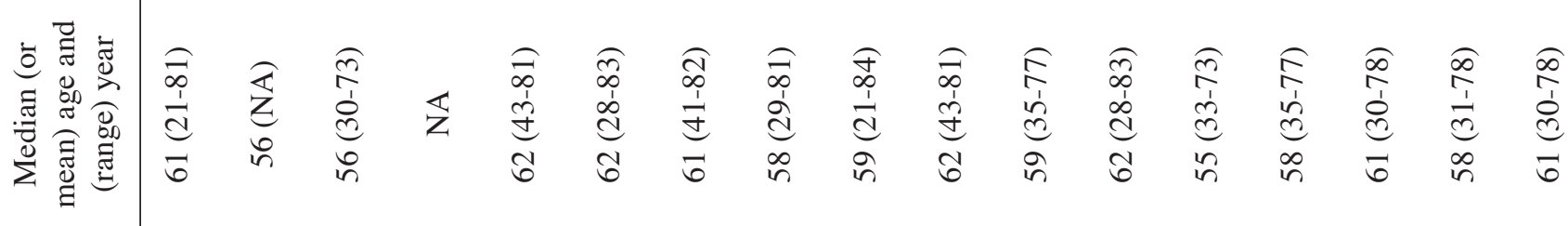

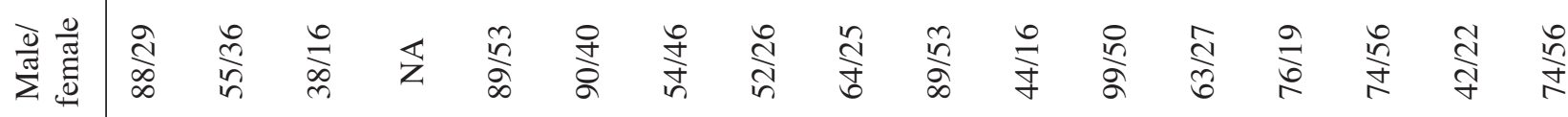

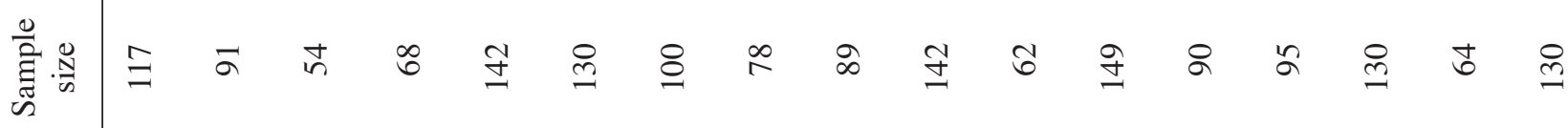

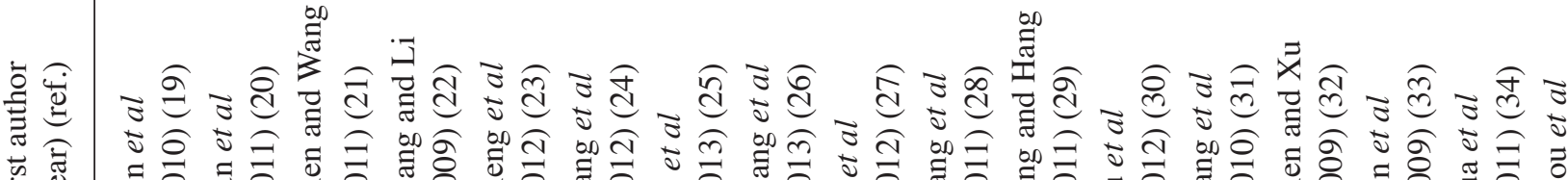

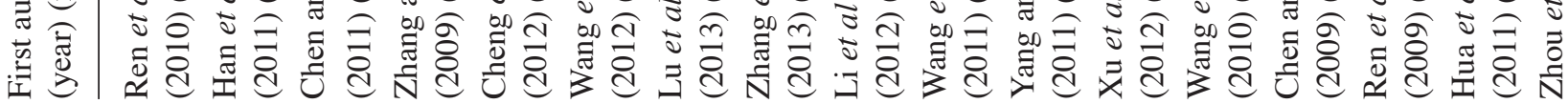




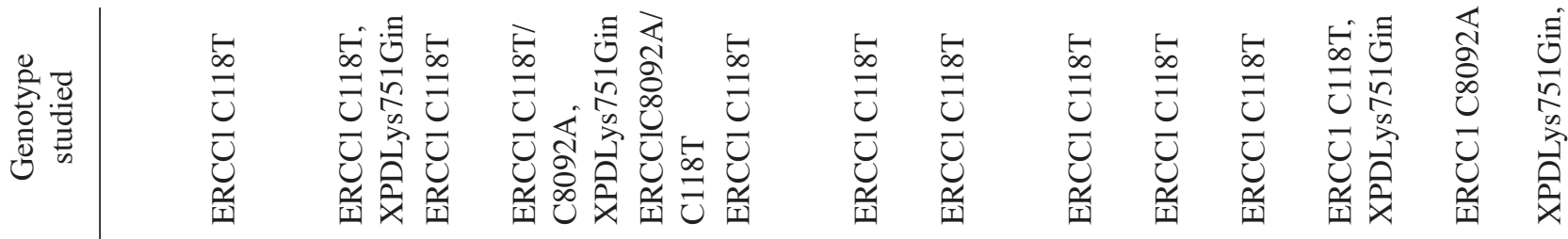

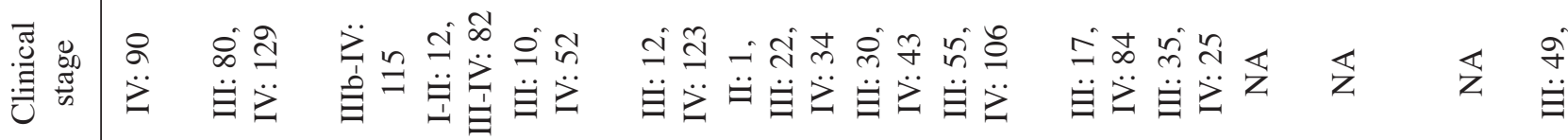

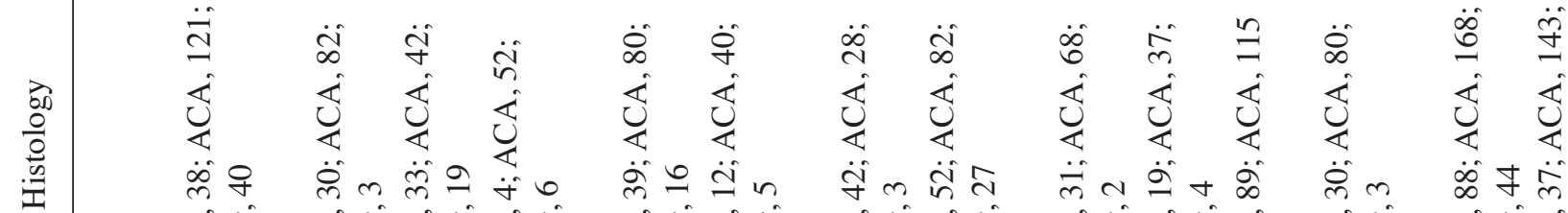

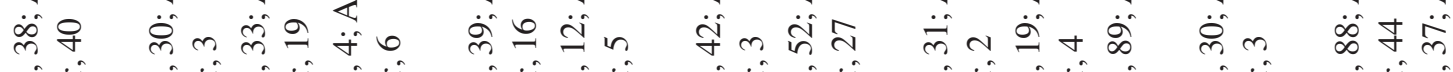

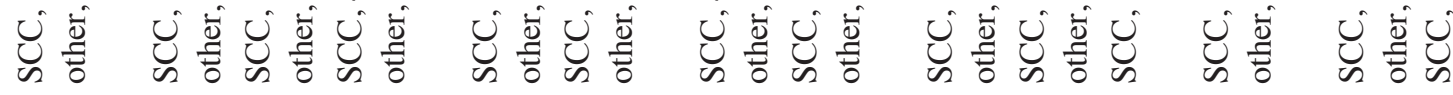

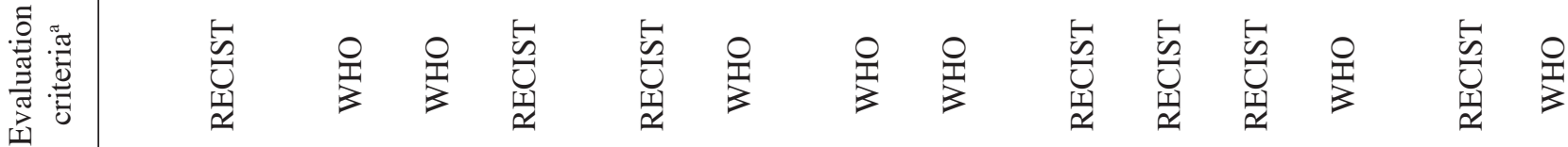

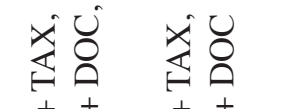

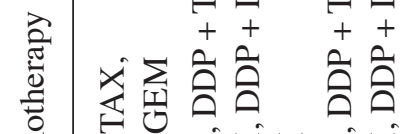

己

$++\sum_{i=1}^{+} \sum_{i=1}^{\infty} \sum_{0}^{\infty}$

$++++++$

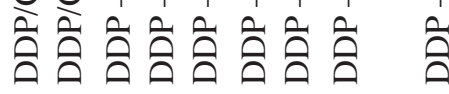

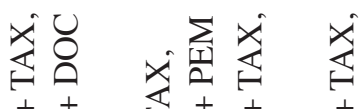

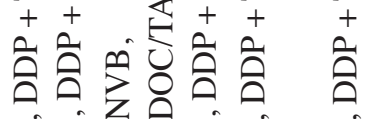

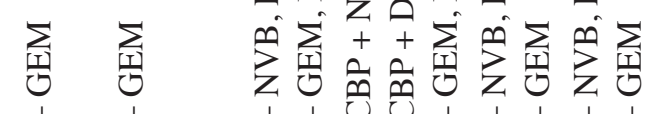

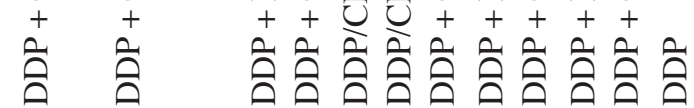

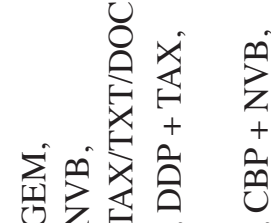

$+++\infty \sum^{n}$

ขึ ขึ

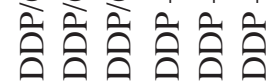

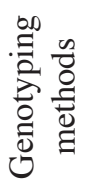

焉

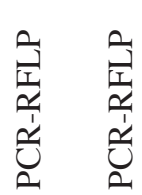

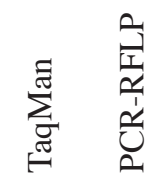

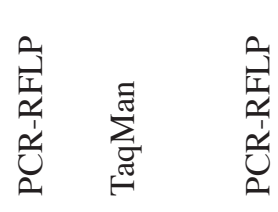

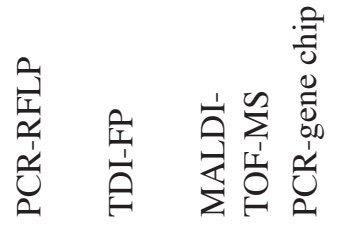

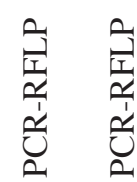

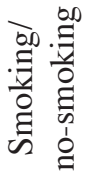

$\overleftrightarrow{z}$

$\underset{+}{\stackrel{f}{o}}$

$\overleftrightarrow{Z}$

$\stackrel{\infty}{\stackrel{n}{\Sigma}} \mathbb{z} \quad \mathbb{z} \underset{\infty}{\stackrel{m}{\infty}}$

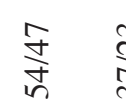

흐 పี

๘

龸芯

a
à
âd

$\widehat{a}$
$\vdots$
$a$
in
in

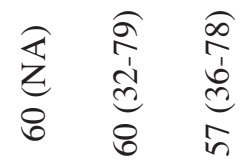

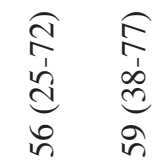

a
1
$d$
$d$
d
in

6
b
0
$n$
$n$

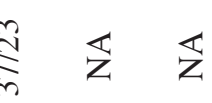

$\underset{i}{\stackrel{P}{z}} \ll$

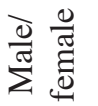

$\sqrt[n]{n}$
$\infty$
$n$

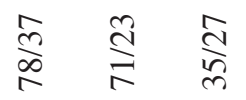

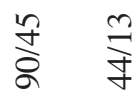

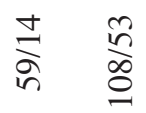

$\frac{7}{8}$

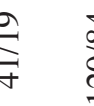

ఏ્ล

$\frac{1}{2}$

๙্ণ

范

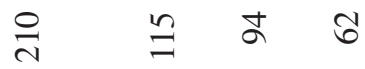

$\approx n$

$\stackrel{6}{1}$

용

ஓ ஓ 


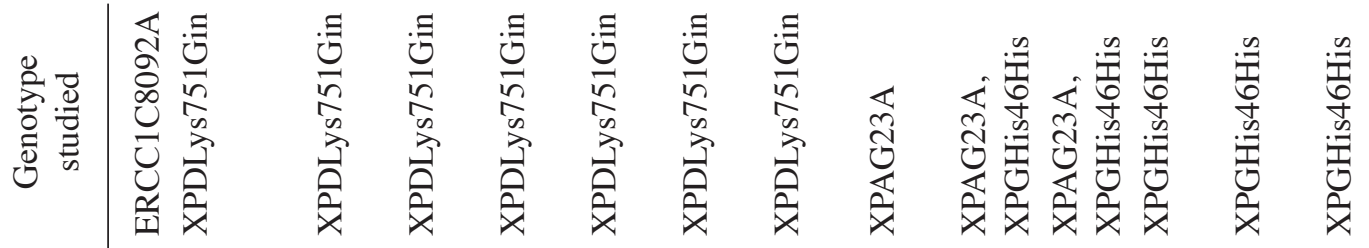

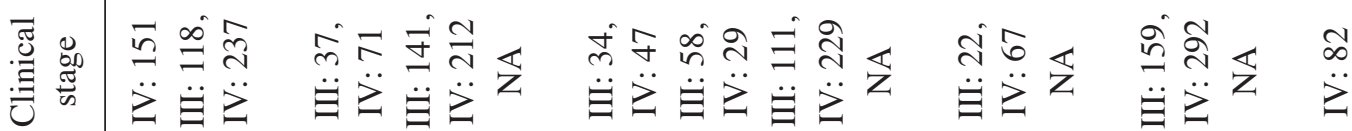

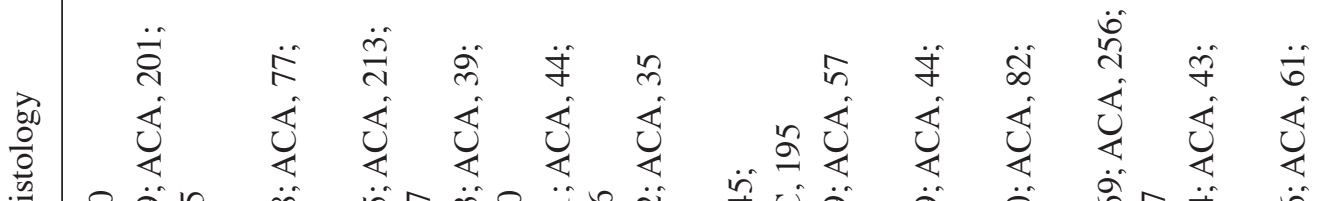

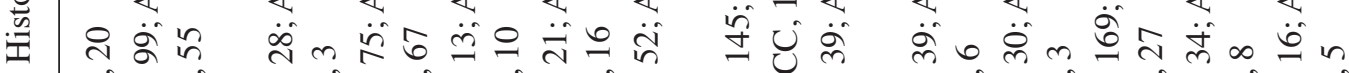

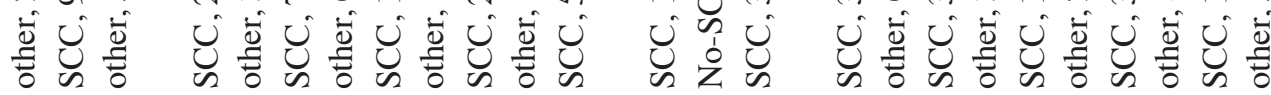

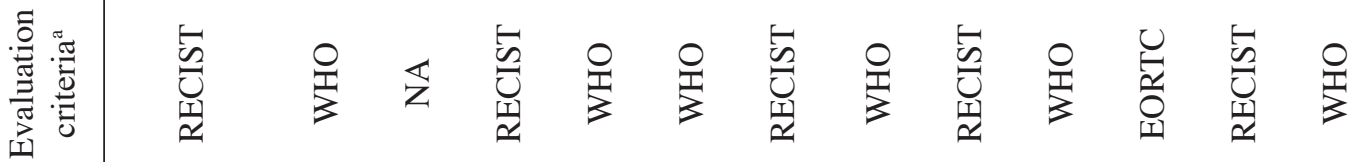

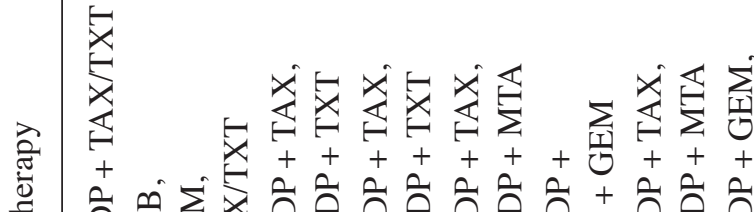

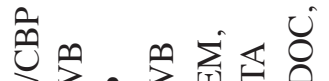

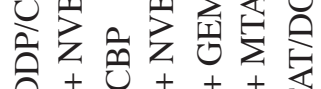

章

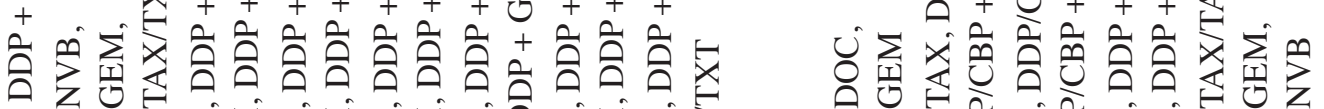
乙讨

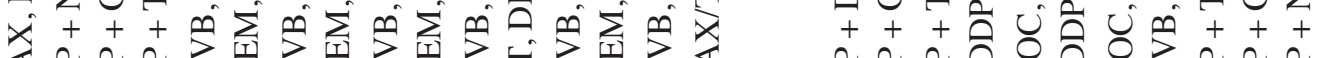

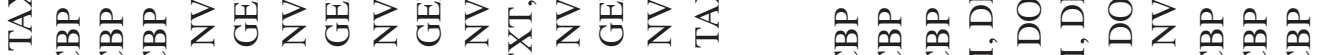

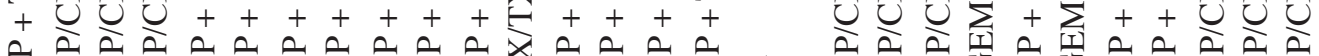

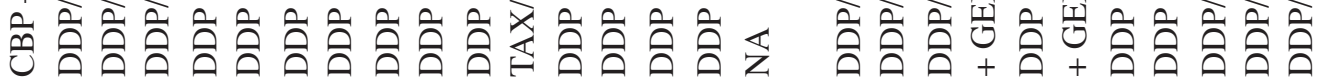

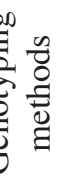

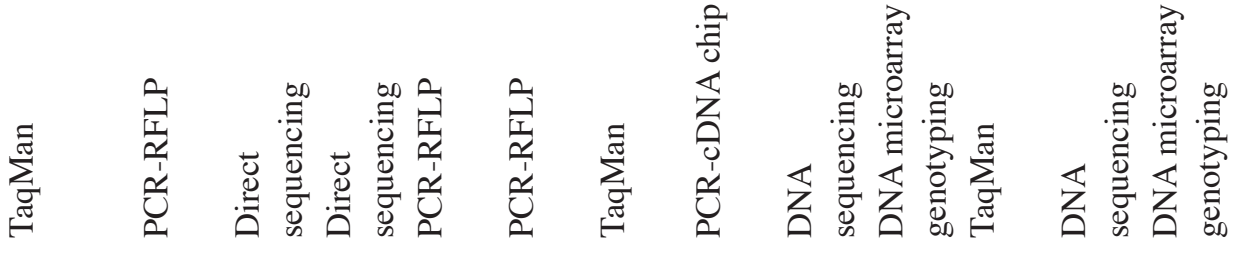

कon

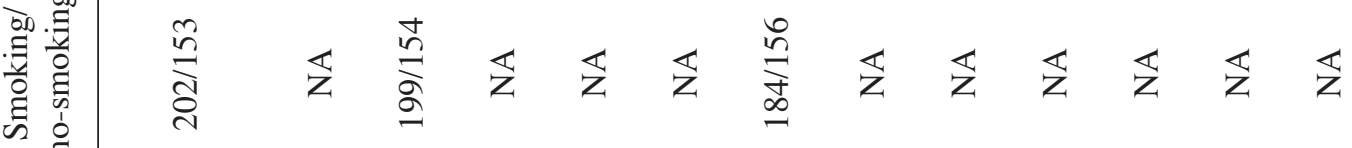

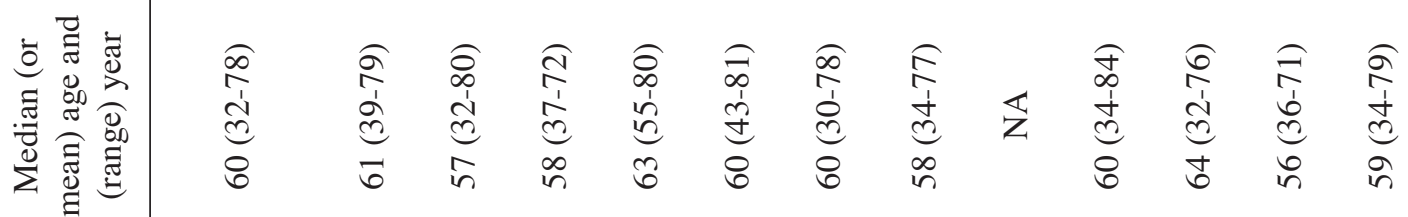

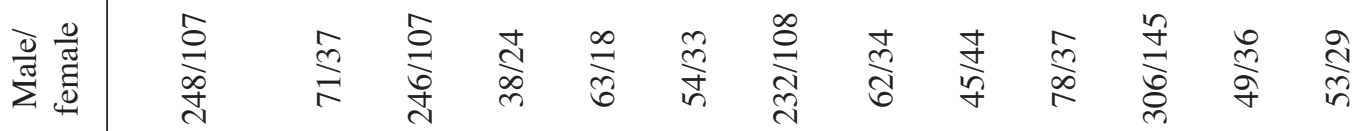

苛芯

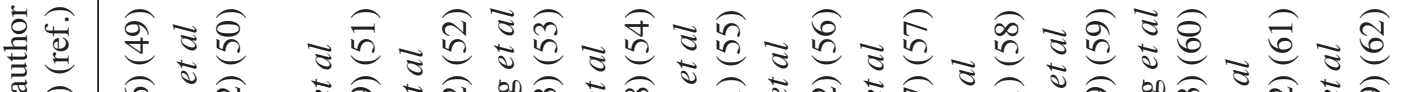

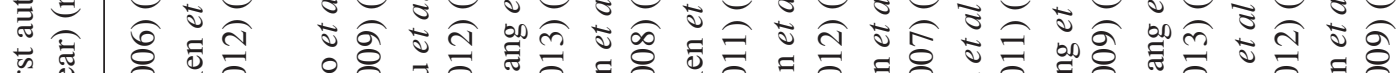

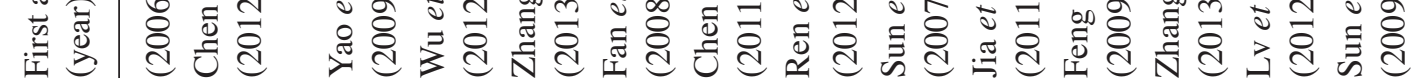

浩

을 응

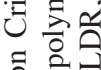

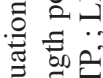

要这

:

율

$\approx$.

on

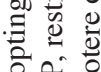

홍

ठ

흥. 
Table II. Summary of the risk ratios (RRs) and 95\% confidence intervals (CIs) of the non-small cell lung cancer risk for contrasts (non-response, stable disease or progressive disease).

\begin{tabular}{|c|c|c|c|c|c|c|c|}
\hline \multirow[b]{2}{*}{ Genetic model } & \multirow{2}{*}{$\begin{array}{l}\text { No. of } \\
\text { studies }\end{array}$} & \multirow{2}{*}{$\begin{array}{c}\text { Pooled RR } \\
(95 \% \mathrm{CI})\end{array}$} & \multirow[b]{2}{*}{ P-value } & \multicolumn{2}{|c|}{ Heterogeneity } & \multirow{2}{*}{$\begin{array}{c}\text { Begg's test } \\
\text { (P-value) }\end{array}$} & \multirow{2}{*}{$\begin{array}{c}\text { Egger's test } \\
\text { (P-value) }\end{array}$} \\
\hline & & & & P-value & $\mathrm{I}^{2}(\%)$ & & \\
\hline \multicolumn{8}{|l|}{ ERCC1 C118T } \\
\hline Homozygote comparison (TT vs. CC) & 8 & $1.01(0.70-1.45)$ & 0.976 & 0.0112 & 61.00 & 0.174 & 0.028 \\
\hline Heterozygote comparison (CT vs. CC) & 8 & $0.91(0.78-1.05)$ & 0.199 & 0.046 & 51.10 & 0.711 & 0.251 \\
\hline Dominant (CT/TT vs. CC) & 21 & $0.95(0.85-1.06)$ & 0.386 & 0.0 & 66.90 & 0.786 & 0.973 \\
\hline Recessive (TT vs. CC/CT) & 11 & $1.06(0.91-1.23)$ & 0.463 & 0.083 & 39.80 & 0.213 & 0.029 \\
\hline \multicolumn{8}{|l|}{ ERCC1 C8092A } \\
\hline Homozygote comparison (AA vs. CC) & 3 & $1.09(0.88-1.35)$ & 0.412 & 0.899 & 0.0 & 1.000 & 0.53 \\
\hline Heterozygote comparison (CA vs. CC) & 3 & $0.94(0.81-1.1)$ & 0.431 & 0.447 & 0.0 & 0.296 & 0.106 \\
\hline Dominant (AA/CA vs. CC) & 8 & $1.11(0.91-1.35)$ & 0.328 & 0.754 & 0.0 & 0.296 & 0.044 \\
\hline Recessive (AA vs. CC/CA) & 3 & $0.96(0.88-1.05)$ & 0.377 & 0.959 & 0.0 & 0.266 & 0.397 \\
\hline \multicolumn{8}{|l|}{ XPD Lys751Gln } \\
\hline Homozygote comparison (GlnGln vs. LysLys) & 3 & $1.21(0.92-1.59)$ & 0.183 & 0.9 & 0.00 & 1.000 & 0.065 \\
\hline Heterozygote comparison (LysGln vs. LysLys) & 7 & $1.08(0.96-1.22)$ & 0.182 & 0.175 & 33.10 & 0.548 & 0.828 \\
\hline Dominant (GlnGln/LysGln vs. LysLys) & 12 & $1.02(0.92-1.13)$ & 0.714 & 0.052 & 43.70 & 0.837 & 0.665 \\
\hline Recessive (GlnGln vs. LysLys/LysGln) & 3 & $1.16(0.89-1.52)$ & 0.272 & 0.925 & 0.0 & 1.000 & 0.022 \\
\hline
\end{tabular}

was detected in Egger's test with $\mathrm{P}>0.05$ (Table II). The shape of the funnel plot did not reveal any evidence of clear asymmetry (data not shown).

Tumor response of XPA A23G and XPG C46T polymorphisms (non-response: $S D$ or $P D$ ). Three studies were included with a total sample size of 300 patients. Overall, this meta-analysis showed that there was no statistically significant association between the XPA $A 23 G$ polymorphism and tumor response for the recessive model (GG/AG vs. AA: $\mathrm{RR}=0.99,95 \% \mathrm{CI}$ : $0.65-1.52, \mathrm{P}=0.969, \mathrm{I}^{2}=80.8 \%$ for heterogeneity test; Table IV). The other three models were not performed as there was no data of interest or raw data.

For the XPG C46T polymorphism, five studies were included with a total sample size of 846 patients. Overall, the meta-analysis showed that there was an increase in the statistically significant association between the XPG C46T polymorphism and tumor response for the three genetic models (TT vs. CC: $\mathrm{RR}=1.31,95 \%$ CI: $1.14-1.5, \mathrm{P}=0.00, \mathrm{I}^{2}=0 \%$ for heterogeneity test; the recessive model, TT vs. CC/CT: $\mathrm{RR}=1.22,95 \%$ CI: $1.11-1.36, \mathrm{P}=0.00, \mathrm{I}^{2}=0 \%$ for heterogeneity test; and the dominant model, TT/CT vs. CC: RR=1.23,95\% CI: 1.11-1.36, $\mathrm{P}=0.00, \mathrm{I}^{2}=0 \%$ for heterogeneity test, Table IV). The XPG C46T polymorphism had no association with tumor response in the heterozygote comparison (CT vs. CC: RR=1.1, 95\% CI: $0.97-1.25, \mathrm{P}=0.136, \mathrm{I}^{2}=0 \%$ for heterogeneity test). In addition, no publication bias was detected in Egger's test with all $\mathrm{P}>0.05$ (Table IV). The shape of the funnel plot did not reveal any evidence of clear asymmetry (data not shown).

\section{Discussion}

A total of 44 studies with 5,944 NSCLC patients were included that examined the ERCC1 C118T/C8092A, ERCC2/XPD A751C,
XPA G23A and XPG C46T polymorphisms. To the best of our knowledge, this is the first meta-analysis elaborating the role of NER gene polymorphisms on the prognosis of platinum-based chemotherapy in Chinese NSCLC patients. However, the overall combined RRs did not support any appreciable association between the ERCC1 C118T/C8092A,XPD A751C and XPA G23A polymorphisms on the prognosis of platinum-based chemotherapy under the four genetic contrast models when SD or PD was defined as non-response, which was consistent with previous meta-analyses $(63,64)$. Additionally, no significant association was obtained for the ERCCl C118T polymorphisms when only PD was considered as non-response. However, elevated associations were observed for the homozygote, dominant and recessive comparisons in the XPG C46T polymorphism, indicating that such gene carriers were more susceptible to platinum-based chemotherapy in Chinese patients with NSCLC.

NER is a highly versatile pathway that is primarily responsible for repairing DNA damage by removing the majority of DNA damage through incisions on both sides of the lesion. The NER pathway is a significant defense mechanism in humans for protection from two major carcinogens; sunlight and cigarette smoke (65). NER has two systems: The repair of strand distortions of the genome by global genome repair and the removal of distorted lesions that block elongating RNA polymerases by transcription-coupled repair (66). There are $>30$ proteins involved in the NER pathway (67). The removal of these platinum adducts, which results in resistance to chemotherapy, is mainly carried out through NER and due to the deficiency of NER, cells are hypersensitive to platinum (68). For the platinum-chemotherapy resistance of NSCLC, there is still no definite predictive biomarker. Regarding the ERCCl C118T/C8092A and XPD A751C polymorphisms on the prognosis of platinum-based chemotherapy in patients with NSCLC, several meta-analyses are available although with inconsistent conclusions from each other (1,63-64,69-70), 
Table III. Summary of the risk ratios (RRs) and 95\% confidence intervals (CIs) of the non-small cell lung cancer risk for contrasts (non-response, progressive disease).

\begin{tabular}{lcccccccc}
\hline & $\begin{array}{c}\text { No. of } \\
\text { studies }\end{array}$ & $\begin{array}{c}\text { Pooled RR } \\
(95 \% \text { CI })\end{array}$ & P-value & P-value & $\mathrm{I}^{2}(\%)$ & $\begin{array}{c}\text { Hegerogeneity } \\
\text { (P-value) }\end{array}$ & $\begin{array}{c}\text { Egger's test } \\
\text { (P-value) }\end{array}$ \\
\hline ERCC1 C118T & & & & & & & \\
Homozygote comparison (TT vs. CC) & 3 & $0.65(0.30-1.41)$ & 0.276 & 0.234 & 31.20 & 1.000 & 0.687 \\
Heterozygote comparison (CT vs. CC) & 3 & $1.00(0.50-2.00)$ & 0.995 & 0.018 & 75.00 & 0.296 & 0.245 \\
Dominant (CT/TT vs. CC) & 7 & $0.83(0.64-1.07)$ & 0.149 & 0.142 & 37.60 & 0.368 & 0.283 \\
Recessive (TT vs. CC/CT) & 3 & $0.67(0.31-1.44)$ & 0.304 & 0.545 & 0.00 & 1.000 & 0.803 \\
\hline
\end{tabular}

A

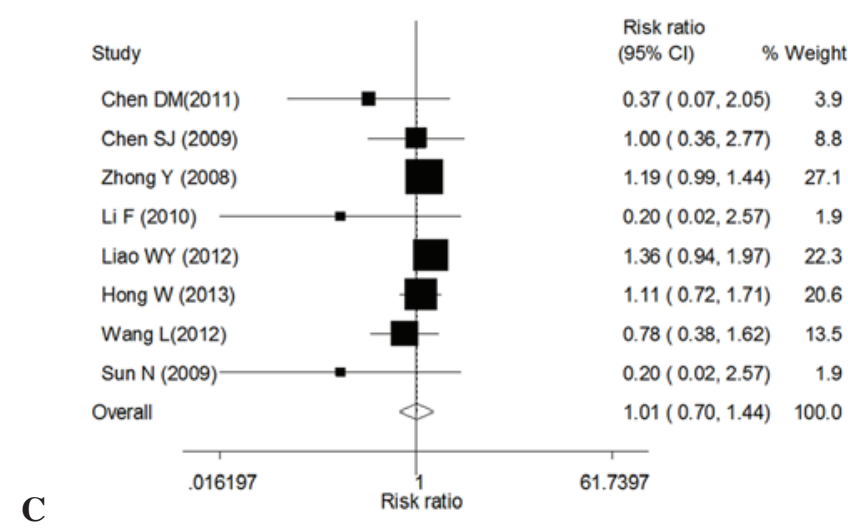

B
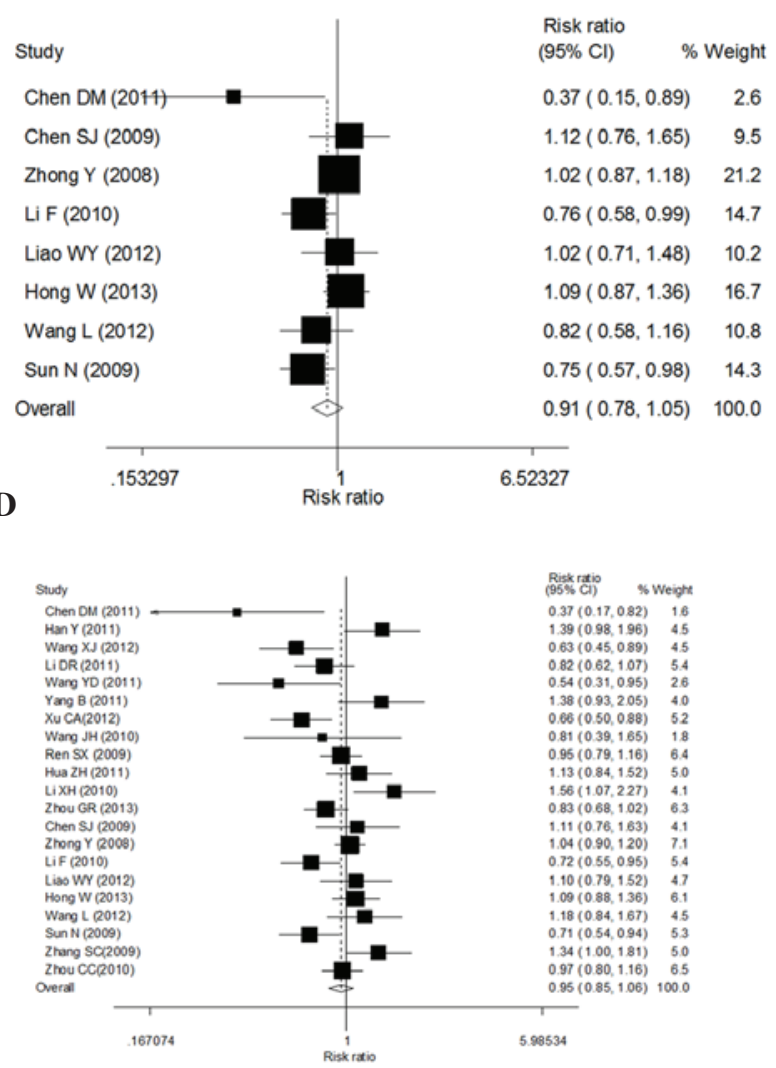

Figure 2. Risk ratios (RRs) and 95\% confidence intervals (CIs) of the individual studies and pooled data for the association between the ERCC1 C118T gene polymorphism and non-small cell lung cancer. The summary of the pooled RR is indicated by a diamond and horizontal lines represent the $95 \% \mathrm{CI}$. (A) T/T vs. C/C; (B) C/T vs. C/C; (C) T/T+C/T vs. C/C; and (D) T/T vs. C/T+C/C.

and certain evidence was found to support the use of the $E R C C 1$ C118T/C8092A and XPD A751C polymorphisms as prognostic predictors of platinum-based chemotherapies in NSCLC. However, its role in Chinese NSCLC patients has not been well-established. Therefore, a meta-analysis of published studies was performed with the aim of clarifying the correlation between five common polymorphisms of four NER genes and prognosis of platinum-based chemotherapy among Chinese NSCLC patients. However, the result showed that the tumor response rate was not significant in patients for ERCC1 C118T/C8092A, XPD A751C and XPA G23A polymorphisms. More interactions of genetic variations and the gene-environment may also be attributed to the prognosis regarding ERCC1, XPD and XPA. Due to these similar mechanisms, the linkage disequilibrium with other genes should be taken into account. The combination with other gene polymorphisms may result in no significant difference. Additionally, unknown regions may contribute to the potential mechanism of ERCC1, XPD and XPA polymorphisms. Regarding the XPG polymorphism, the total sample size was limited and the positive results required further confirmation. 
Table IV. Summary of the risk ratios (RRs) and 95\% confidence intervals (CIs) of the non-small cell lung cancer risk for contrasts (non-response, stable disease or progressive disease).

\begin{tabular}{|c|c|c|c|c|c|c|c|}
\hline \multirow[b]{2}{*}{ Genetic model } & \multirow{2}{*}{$\begin{array}{l}\text { No. of } \\
\text { studies }\end{array}$} & \multirow{2}{*}{$\begin{array}{c}\text { Pooled RR } \\
(95 \% \text { CI) }\end{array}$} & \multirow[b]{2}{*}{ P-value } & \multicolumn{2}{|c|}{ Heterogeneity } & \multirow{2}{*}{$\begin{array}{c}\text { Begg's test } \\
\text { (P-value) }\end{array}$} & \multirow{2}{*}{$\begin{array}{c}\text { Egger's test } \\
\text { (P-value) }\end{array}$} \\
\hline & & & & P-value & $\mathrm{I}^{2}(\%)$ & & \\
\hline \multicolumn{8}{|l|}{ XPA A23G } \\
\hline Recessive (GG/AG vs. AA) & 3 & $0.99(0.65-1.52)$ & 0.969 & 0.001 & 80.80 & 0.734 & 0.694 \\
\hline \multicolumn{8}{|l|}{ XPG C46T } \\
\hline Homozygote comparison (TT vs. CC) & 3 & $1.31(1.14-1.5)$ & 0.000 & 0.915 & 0.00 & 0.296 & 0.136 \\
\hline Heterozygote comparison (CT vs. CC) & 3 & $1.10(0.97-1.25)$ & 0.136 & 0.651 & 0.00 & 1.000 & 0.791 \\
\hline Dominant (TT/CT vs. CC) & 5 & $1.23(1.11-1.36)$ & 0.000 & 0.480 & 0.00 & 0.806 & 0.143 \\
\hline Recessive (TT vs. CC/CT) & 3 & $1.22(1.11-1.36)$ & 0.000 & 0.564 & 0.00 & 1.000 & 0.907 \\
\hline
\end{tabular}

A

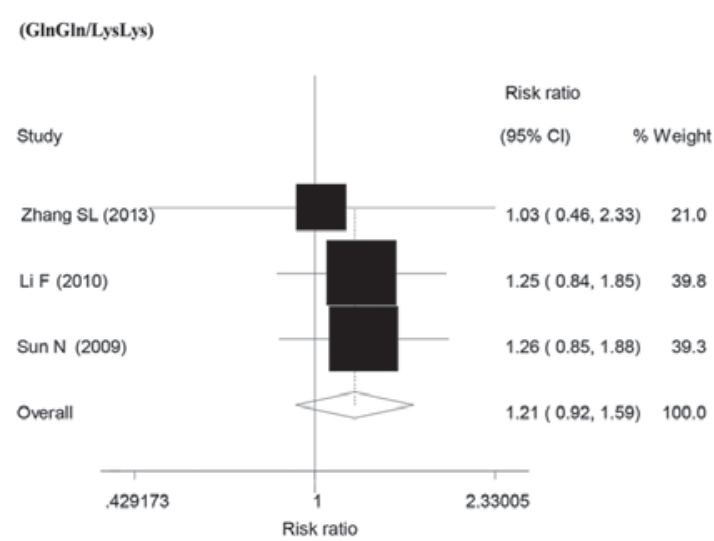

C

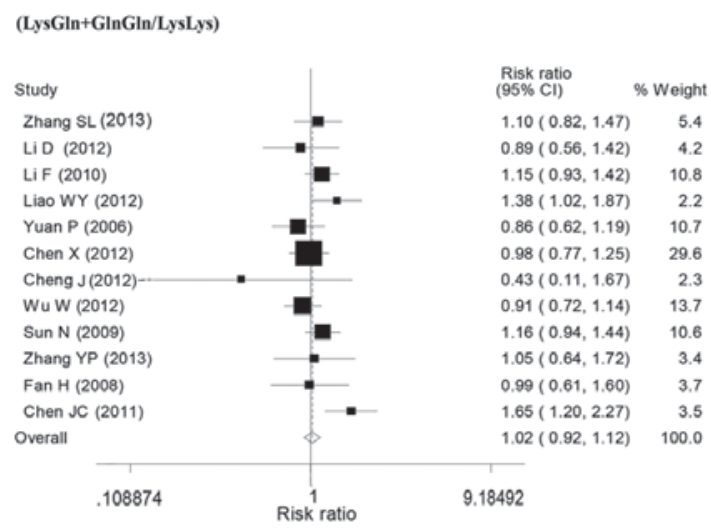

B

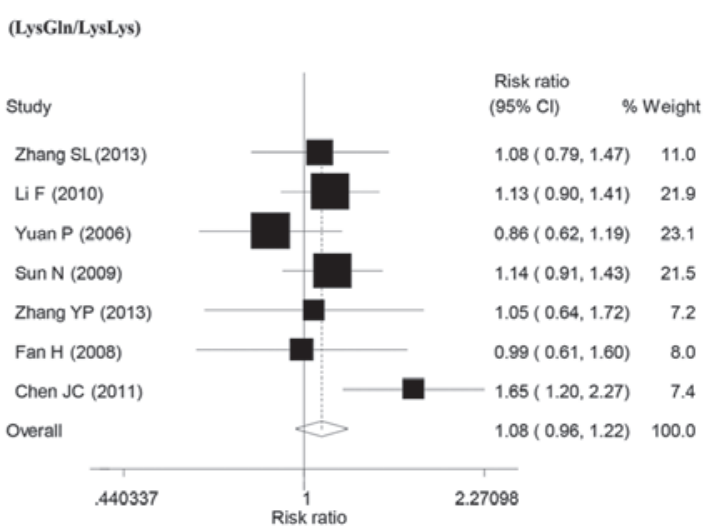

D

$(G \ln G \ln / L y s G \ln +\mathrm{LysL} y s)$

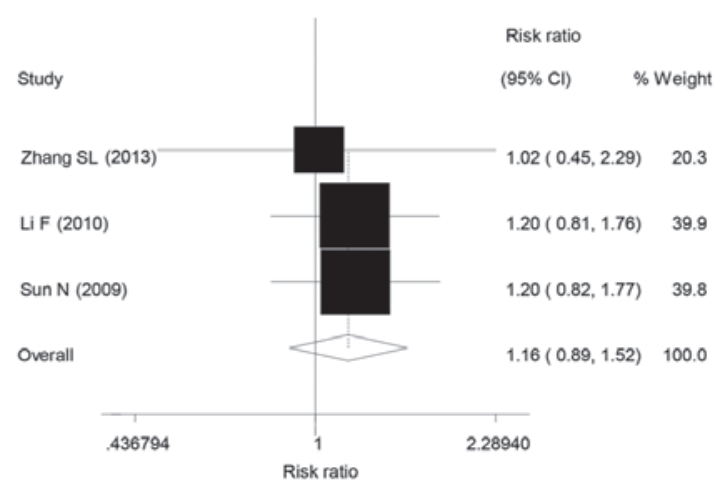

Figure 3. Risk ratios (RRs) and 95\% confidence intervals (CIs) of the individual studies and pooled data for the association between the XPD Lys $751 G l n$ gene polymorphism and non-small cell lung cancer. The summary of the pooled RR is indicated by a diamond and horizontal lines represent the $95 \%$ CI. (A) GlnGln/LysLys; (B) LysGln/LysLys; (C) LysGln + GlnGln/LysLys; and (D) GlnGln/LysGln + LysLys.

Potential limitations of the current study should be acknowledged. First, heterogeneity is a noteworthy issue in a meta-analysis and one of the most significant goals of meta-analysis is identifying the sources of heterogeneity. The study on the XPD A751C and XPA A23G polymorphism observed evidence of significant heterogeneity. A large heterogeneity between studies was always identified in certain comparisons, which could interfere with the interpretation of the findings of a meta-analysis. There may be additional potential sources of heterogeneity besides the aforementioned reason, however, owing to a lack of access to original source data, these sources were not investigated further in subgroup analyses according to ethnicity. Second, although evaluation of specific potential confounding factors was attempted, including age distribution, gender, nutrition, alcohol abuse, family history, lifestyle, dietary habits, body mass index, smoking status and stress, the similar environmental conditions and the definition of each stratum varied among studies and were 
reported in only a limited number of studies. A more precise analysis should be conducted based on the adjusted estimates. Third, owing to only published studies being included in the meta-analysis, it is extremely possible that other unpublished studies and published studies in languages other than English and Chinese may have been omitted. Therefore, the possibility of a larger sample size and increased statistical power may have been missed. Fourth, the meta-analysis is based on unadjusted estimates, and the availability of individual date potentially allows for more precise analysis. Owing to a lack of interest/complementary data, the opportunity allowing for an adjustment estimate was lost (at least for age and smoking). Fifth, little observation on the gene-gene and gene-environment interactions may be responsible for the unstable results. Notably, the majority of these studies were retrospective studies. Additionally, as a significant impact factor, the tumor description, including classification and stages, may also be accountable for the inconsistent results. The analysis also failed to demonstrate the influence of the ERCC1, XPD, XPG and $X P A$ polymorphisms on survival and progression-free survival rates with a lack of interest/complementary data. Taking these potential limitations into consideration, the results may not have enough statistical power to explore the association of these polymorphisms with NSCLC susceptibility.

In conclusion, no evidence was found to support the use of the ERCC1 C118T/C8092A, XPD Lys751Gln and XPA A23G polymorphisms as prognostic predictors of platinum-based chemotherapies in NSCLC treatment based on the current published data in the meta-analysis. For the XPG C46T polymorphism, there was a significant association with an objective response detected. However, occasional studies could not be ruled out due to the limited number of subjects examined and observation of between-study heterogeneity. Additional genetic epidemiological investigations that are well designed and have large samples for these findings are required for the association between biomarkers and tumor prognosis.

\section{Acknowledgements}

The authors would like to thank all the participants of the study. The present study was not supported by any grants.

\section{References}

1. Xu TP, Shen H,Liu LX and Shu YQ: Association of ERCC1-C118T and -C8092A polymorphisms with lung cancer risk and survival of advanced-stage non-small cell lung cancer patients receiving platinum-based chemotherapy: a pooled analysis based on 39 reports. Gene 526: 265-274, 2013.

2. Jemal A, Siegel R, Ward E, et al: Cancer statistics, 2007. CA Cancer J Clin 57: 43-66, 2007.

3. Xing D, Tan W, Wei Q and Lin D: Polymorphisms of the DNA repair gene XPD and risk of lung cancer in a Chinese population. Lung Cancer 38: 123-129, 2002.

4. Jemal A, Siegel R, Ward E, et al: Cancer statistics, 2009. CA Cancer J Clin 59: 225-249, 2009.

5. Pujol JL, Barlesi F and Daurès JP: Should chemotherapy combinations for advanced non-small cell lung cancer be platinum-based? A meta-analysis of phase III randomized trials. Lung Cancer 51: 335-345, 2006.

6. Ohe Y, Ohashi Y, Kubota K, et al: Randomized phase III study of cisplatin plus irinotecan versus carboplatin plus paclitaxel, cisplatin plus gemcitabine, and cisplatin plus vinorelbine for advanced non-small-cell lung cancer: Four-Arm Cooperative Study in Japan. Ann Oncol 18: 317-323, 2007.
7. Rosell R, Cecere F, Santarpia M, et al: Predicting the outcome of chemotherapy for lung cancer. Curr Opin Pharmacol 6: 323-331, 2006.

8. Jun L, Haiping Z and Beibei Y: Genetic polymorphisms of GSTP1 related to response to 5-FU-oxaliplatin-based chemotherapy and clinical outcome in advanced colorectal cancer patients. Swiss Med Wkly 139: 724-728, 2009.

9. Ronen A and Glickman BW: Human DNA repair genes. Environ Mol Mutagen 37: 241-283, 2001.

10. Wei Q and Spitz MR: The role of DNA repair capacity in susceptibility to lung cancer: a review. Cancer Metastasis Rev 16: 295-307, 1997.

11. Goode EL, Ulrich CM and Potter JD: Polymorphisms in DNA repair genes and associations with cancer risk. Cancer Epidemiol Biomarkers Prev 11: 1513-1530, 2002.

12. van Hoffen A, Balajee AS, van Zeeland AA and Mullenders LH: Nucleotide excision repair and its interplay with transcription. Toxicology 193: 79-90, 2003

13. Choi JH, Ahn MJ, Rhim HC, et al: Comparison of WHO and RECIST criteria for response in metastatic colorectal carcinoma. Cancer Res Treat 37: 290-293, 2005.

14. DerSimonian R and Laird N: Meta-analysis in clinical trials. Control Clin Trials 7: 177-188, 1986.

15. Cochran WG: The comparison of percentages in matched samples. Biometrika 37: 256-266, 1950.

16. Higgins JP, Thompson SG, Deeks JJ and Altman DG: Measuring inconsistency in meta-analyses. BMJ 327: 557-560, 2003.

17. Begg CB and Mazumdar M: Operating characteristics of a rank correlation test for publication bias. Biometrics 50: 1088-1101, 1994

18. Egger M, Davey Smith G, Schneider M and Minder C: Bias in meta-analysis detected by a simple, graphical test. BMJ 315: 629-634, 1997

19. Ren BH, Yang X, Li M, et al: Single nucleotide polymorphisms in DNA repair gene ERCCl predict clinical response to platinum-based chemotherapy in non-small cell lung cancer. Chin J Exp Surg 27: 1200-1202, 2010.

20. Han Y, Liang J, Lv HY, et al: ERCC1 and XRCC1 gene polymorphisms and clinical response to platinum-based chemotherapy in advanced non-small cell lung cancer. Chin J Prac Intern Med 31: 638-639, 2011

21. Chen DM and Wang NJ: Association of the protein expression and gene polymorphisms in DNA repair genes XRCC1, ERCC1, RRM1 and the effect of platinum-based regimens chemotherapy in advanced non-small cell lung cancer patients. $\mathrm{PhD}$ dissertation, Michigan State University. MM dissertation, Ningxia Med Univ, ProQuest, 2011.

22. Zhang SC and Li Q: Clinical significance of expression of ERCC1, class III $\beta$-tubulin in resected patients with non-small cell lung cancer and association between polymorphisms of ERCC1 and response and survival in advanced non-small cell lung cancer patients treated with cisplatin-based chemotherapy. PhD dissertation, The Tuberculosis Thoracic Tumor Research Institute of Beijing, ProQuest, 2009.

23. Cheng J, Ha M, Wang Y, et al: A C118T polymorphism of ERCC 1 and response to cisplatin chemotherapy in patients with late-stage non-small cell lung cancer. J Cancer Res Clin Oncol 138: 231-238, 2012.

24. Wang XJ, Xu CA, Zhang Y, et al: Relationship between ERCC1 and XPD genetic polymorphism and sensitivity of platinum-based chemotherapy in advanced non-small cell lung cancer. Chin Gen Pract 15: 1010-1014, 2012.

25. Lu HD, Cui EH and Hua F: The association between the susceptibility to platinum drugs and the genetic polymorphisms of ERCC 1 and BAG-1 in patients with advanced non-small cell lung cancer. China Modern Doctor 51: 65-67, 2013.

26. Zhang SL, Zhang ZL and Shi MH: Association between polymorphisms of ERCC1 and XPD and sensitivity to platinum-based chemotherapy in advanced non-small cell lung cancer. Jiangsu Med J 39: 303-305, 2013.

27. Li D, Zhou Q, Liu Y, et al: DNA repair gene polymorphism associated with sensitivity of lung cancer to therapy. Med Oncol 29: 1622-1628, 2012

28. Wang YD, Cheng J, Chen JC, et al: The association of genetic polymorphisms of BAG-1 and $\mathrm{ERCCl}$ with the clinical response to platinum drugs in patients with advanced non-small cell lung cancer. Tumor 31: 824-829, 2011.

29. Yang B and Hang FC: Polymorphisms in ERCC1, RRM1 genes and sensitivity to gemcitabine/cisplatin chemotherapy in advanced non-small cell lung cancer. MM dissertation, Shanxi Med Univ, ProQuest, 2011. 
30. Xu CA, Li Q, Wang XJ, et al: Sensitivity relationship of ERCC1 and XRCC1 genetic polymorphism on response of platinum-based chemotherapy in advanced NSCLC. J Pract Oncol 27: 245-250, 2012.

31. Wang J, Zhang Q, Zhang H, et al: Association between polymorphisms of ERCC1 and response in patients with advanced non-small cell lung cancer receiving cisplatin-based chemotherapy. Zhongguo Fei Ai Za Zhi 13: 337-341, 2010 (In Chinese).

32. Chen SJ and Xu XJ: The relationship between MDR1 and ERCC1 genetic polymorphisms and haplotype response rate of platinum-based chemotherapy and side effect on non-small cell lung cancer therapy. MM dissertation, Shantou University, ProQuest, 2009.

33. Ren SX, Zhou CC, Zhou SW, et al: Predictive role of ERCC and XRCC3 gene polymorphism on response of platinum-based chemotherapy in advanced NSCLC. J Oncol 15: 706-710, 2009.

34. Hua ZH, Fang WZ, Zhao ZQ, et al: Association study of ERCC1 and ERCC4 genetic polymorphism with response and survival in non-small cell lung cancer patients treated with cisplatin-based chemotherapy. Acta Metallurgica Sinica 16: 772-778, 2011.

35. Zhou C, Ren S, Zhou S, et al: Predictive effects of ERCC1 and XRCC3 SNP on efficacy of platinum-based chemotherapy in advanced NSCLC patients. Jpn J Clin Oncol: 40: 954-960, 2010.

36. Zhong Y, Lu DR, Han BH, et al: The association study of ERCCl polymorphism and chemotherapy response/toxicity of lung cancer. MM dissertation, Fudan University, ProQuest, 2008.

37. Li F, Sun X, Sun N, et al: Association between polymorphisms of ERCC1 and XPD and clinical response to platinum-based chemotherapy in advanced non-small cell lung cancer. Am J Clin Oncol 33: 489-494, 2010.

38. Liu YF, Guan XX, Chen LB, et al: Study on ERCC1, XPD and XPA polymorphisms for prediction of platinum-based chemotherapy sensitivity in non-small cell lung cancer. Chin J Cancer Prev Treat 15: 1285-1288, 2008

39. Liao WY, Shih JY, Chang GC, et al: Genetic polymorphism of XRCC1 Arg399Gln is associated with survival in non-small-cell lung cancer patients treated with gemcitabine/platinum. J Thorac Oncol 7: 973-981, 2012

40. Hong W, Wang K, Zhang YP, et al: Methylenetetrahydrofolate reductase $\mathrm{C677T}$ polymorphism predicts response and time to progression to gemcitabine-based chemotherapy for advanced non-small cell lung cancer in a Chinese Han population. J Zhejiang Univ Sci B 14: 207-215, 2013.

41. Gao CM, Shi MQ, Wu JZ, et al: Polymorphisms in ERCC1, $\mathrm{XRCCl}$ genes and sensitivity to gemcitabine/cisplatin chemotherapy in non-small cell lung cancer. Chin J Cancer Prey Treat 16: 27-30, 2010

42. Jin YF, Li TC, Wang Y, et al: Single nucleotide polymorphisms in ERCCl and XPD genes and sensitivity to platinum-based chemotherapy in non-small-cell Iung cancer. Carcinogenesis, Teratogenesis \& Mutagenesis 22: 374-378, 2010.

43. Su T and Cao GW: Associations of DNA repair gene, MDR1, and PTPRD polymorphisms with chemotherapy and survival in lung cancer patients. MM dissertation, Second Military Medical University, ProQuest, 2012.

44. Wang L, Dai XF, Wu G, et al: Predictive value of excision repair cross-complementation group $1(\mathrm{ERCCl})$ polymorphism on chemotherapy response and survival of advanced non-small cell lung cancer patients treated with cisplatin. Herald Med 31: 720-724, 2012

45. Li XH, Jiang WF, Zhang HL, et al: Relationship between SNPs of ERCC1 in peripheralblood of NSCLC and effects of cisplatin-based chemotherapy. Chin J Cancer Prev Treat 17: 169-172, 2010.

46. Zhou GR, Feng JF, Lu JW, et al: On sensitivity of XRCC1 and ERCC1 single nucleotide polymorphism and non-small cell lung cancer to platinum-based chemotherapy: J Hainan Med Univ 20 20-24, 2013.

47. Sun N, Chen BA and Sun XC: Association between single nucleotide polymorphisms of some genes and clinical response to platinum-based chemotherapy in advanced non-small cell lung cancer (PhD thesis). Southeast University, 2009.

48. KimCurran V, Zhou C, Schmid-Bindert G, et al: Lack of correlation between ERCC1 (C8092A) single nucleotide polymorphism and efficacy/toxicity of platinum based chemotherapy in Chinese patients with advanced non-small cell lung cancer. Adv Med Sci 56: 30-38, 2011.

49. Yuan P, Miao XP, Zhang XM, et al: XRCCl and XPD genetic polymorphisms predict clinical responses to platinum-based chemotherapy in advanced non-small cell lung cancer. Zhonghua Zhong Liu Za Zhi 28: 196-199, 2006 (In Chinese).
50. Chen X, Sun H, Ren S, et al: Association of XRCC3 and XPD75 SNP with efficacy of platinum-based chemotherapy in advanced NSCLC patients. Clin Transl Oncol 14: 207-213, 2012.

51. Yao CY, Huang XE, Li C, et al: Lack of influence of XRCC1 and XPD gene polymorphisms on outcome of platinum-based chemotherapy for advanced non small cell lung cancers. Asian Pac J Cancer Prev 10: 859-864, 2009.

52. Wu W, Li H, Wang H, et al: Effect of polymorphisms in XPD on clinical outcomes of platinum-based chemotherapy for Chinese non-small cell lung cancer patients. PLoS One 7: e33200, 2012.

53. Zhang YP, Xue HB, Ling Y, et al: Correlation between the polymorphisms in XPD751 gene and sensitivity and toxicity of chemotherapy in advanced non-small cell lung cancer. Hainan Med J 24: 648-650, 2013

54. Fan H, Huang XE, Zhang Q, et al: Relationship of XRCC1 and XPD gene polymorphisms with chemosensitivity to platinum-based chemotherapy in advanced non-small cell lung cancer. Pract Geriatr 22: 306-314, 2008 (In Chinese).

55. Chen JC, Liu ZL, Cheng J, et al: Relationship between XPD single nudeotide polymorphisms and platinum sensitivity in advanced non-small cell lung Cancer. Chin J Gerontol 31: 1114-1117, 2011 (In Chinese).

56. Ren S, Zhou S, Wu F, et al: Association between polymorphisms of DNA repair genes and survival of advanced NSCLC patients treated with platinum-based chemotherapy. Lung Cancer 75 102-109, 2012.

57. Sun XC, Su N, Cheng HY, et al: XPA A23G polymorphism and clinical response to platin-based chemotherapy in advanced non-small cell lung cancer. J Med Postgrad 20: 1271-1273, 2007.

58. Jia XF, Liang J, Lv HY, et al: Relationship between XPA and XPG polymorphisms and platinum-based chemotherapy outcomes in advanced non-small cell lung cancer. Prog Mod Biomed 11: $1718-1722,2011$.

59. Feng J, Sun X, Sun N, et al: XPA A23G polymorphism is associated with the elevated response to platinum-based chemotherapy in advanced non-small cell lung cancer. Acta Biochim Biophys Sin (Shanghai) 41: 429-435, 2009.

60. Zhang T, Sun J, Lv M, et al: XPG is predictive gene of clinical outcome in advanced non-small-cell lung cancer with platinum drug therapy. Asian Pac J Cancer Prev 14: 701-705, 2013.

61. Lv HY, Li QC, Wei HJ, et al: Relationship between GSTP1 and XPG genetic polymorphisms and survival of platinum-based chemotherapy in advanced non-small cell lung cancer patients. China Oncol 22: 609-617, 2012.

62. Sun X, Li F, Sun N, et al: Polymorphisms in XRCC1 and XPG and response to platinum-based chemotherapy in advanced non-small cell lung cancer patients. Lung Cancer 65: 230-236, 2009.

63. Yin M, Yan J, Voutsina A, et al: No evidence of an association of ERCC1 and ERCC2 polymorphisms with clinical outcomes of platinum-based chemotherapies in non-small cell lung cancer: a meta-analysis. Lung Cancer 72: 370-377, 2011.

64. Yu D, Shi J, Sun T, et al: Pharmacogenetic role of ERCC1 genetic variants in treatment response of platinum-based chemotherapy among advanced non-small cell lung cancer patients. Tumour Biol 33: 877-884, 2012.

65. Machius M, Henry L, Palnitkar M and Deisenhofer J: Crystal structure of the DNA nucleotide excision repair enzyme UvrB from Thermus thermophilus. Proc Natl Acad Sci USA 96 $11717-11722,1999$.

66. Hoeijmakers JH: DNA damage, aging, and cancer. N Engl J Med 361: 1475-1485, 2009.

67. Friedberg EC: DNA damage and repair. Nature 421: 436-440, 2003.

68. Furuta T, Ueda T, Aune G, et al: Transcription-coupled nucleotide excision repair as a determinant of cisplatin sensitivity of human cells. Cancer Res 62: 4899-4902, 2002

69. Wei HB, Hu J, Shang LH, et al: A meta-analytic review of ERCC1/MDR1 polymorphism and chemosensitivity to platinum in patients with advanced non-small cell lung cancer. Chin Med J (Engl) 125: 2902-2907, 2012.

70. Wei SZ, Zhan P, Shi MQ, et al: Predictive value of ERCC1 and XPD polymorphism in patients with advanced non-small cell lung cancer receiving platinum-based chemotherapy: a systematic review and meta-analysis. Med Oncol 28: 315-321, 2011. 